\title{
Growth of Chlamydomonas reinhardtii in acetate-free medium when co-cultured with alginate-encapsulated, acetate-producing strains of Synechococcus sp. PCC 7002
}

\author{
Jesse B Therien ${ }^{1}$, Oleg A Zadvornyy ${ }^{1}$, Matthew C Posewitz ${ }^{3}$, Donald A Bryant ${ }^{1,2}$ and John W Peters ${ }^{1 *}$
}

\begin{abstract}
Background: The model alga Chlamydomonas reinhardtii requires acetate as a co-substrate for optimal production of lipids, and the addition of acetate to culture media has practical and economic implications for algal biofuel production. Here we demonstrate the growth of $C$. reinhardtii on acetate provided by mutant strains of the cyanobacterium Synechococcus sp. PCC 7002.

Results: Optimal growth conditions for co-cultivation of C. reinhardtii with wild-type and mutant strains of Synechococcus sp. 7002 were established. In co-culture, acetate produced by a glycogen synthase knockout mutant of Synechococcus sp. PCC 7002 was able to support the growth of a lipid-accumulating mutant strain of C. reinhardtii defective in starch production. Encapsulation of Synechococcus sp. PCC 7002 using an alginate matrix was successfully employed in co-cultures to limit growth and maintain the stability.

Conclusions: The ability of immobilized strains of the cyanobacterium Synechococcus sp. PCC 7002 to produce acetate at a level adequate to support the growth of lipid-accumulating strains of $C$. reinhartdii offers a potentially practical, photosynthetic alternative to providing exogenous acetate into growth media.
\end{abstract}

Keywords: Biofuels, Algae, Cyanobacteria, Lipid production, Acetate production, Co-culture, Alginate immobilization

\section{Background}

With the ongoing increase in global energy demand, the development of alternative energy sources has been at the forefront of recent modern research. Of the various alternative energies, bioenergy has been of interest because of its many potential benefits over the currently used petroleum, natural gas, and coal. These benefits include carbon neutrality, renewability, low environmental toxicity, and reduction of dependence on foreign energy sources. Biodiesel and bioethanol, which together currently account for the major proportion of biofuels, are mainly produced from higher plants [1]. These fuels can replace diesel and gasoline, respectively, in conventional engines without modification. Of these two biofuels,

\footnotetext{
*Correspondence: john.peters@chemistry.montana.edu

1 Department of Chemistry and Biochemistry, Montana State University, Bozeman, Montana 59717, USA

Full list of author information is available at the end of the article
}

biodiesel has been considered the most viable option in the United States [2]. However, the production of biodiesel from crops grown on arable land is controversial due to the potential implications of the competition with agricultural food production [3,4]. One alternative to using food crops as oil sources is to produce biofuels using microalgae and/or cyanobacteria, which can be grown in areas not suitable for crop growth, such as deserts [5,6]. Microalgae can be used to assimilate $\mathrm{CO}_{2}$ and produce multiple fuel molecules, including hydrogen, starch, and lipids [7-9]. Starch can be fermented to hydrogen or ethanol, while lipids can be converted to biodiesel [10-12].

Some lipid-accumulating microalgae, such as Chlamydomonas reinhardtii, are able to grow photoautotrophically on sunlight and $\mathrm{CO}_{2}$, chemotrophically on acetate, or photomixotrophically in a combination of these two growth modes $[13,14]$. Optimal lipid production by C. reinhardtii 
is observed under photomixotrophic conditions in the presence of acetate, which could present economic and practical challenges for large-scale production of algalbased biofuels $[15,16]$. An alternative is to co-culture lipid-producing $C$. reinhardtii with an acetate-producing cyanobacterium, such as certain Synechococcus sp., that can naturally produce acetate during photosynthesis and/ or fermentation [17-19].

In this study, we present results of co-culturing wild-type and a lipid-accumulating (sta6) strain of $C$. reinhardtii, and an acetate-accumulating strain ( $g \lg A 1)$ of Synechococcus sp. PCC 7002. We demonstrate sustained photomixotrophic growth of $C$. reinhardtii with acetate produced by Synechococcus 7002 .

\section{Results and discussion}

Effect of temperature on growth of Synechococcus sp. PCC 7002 and C. reinhardtii

To determine conditions under which both organisms could grow well together, the wild-type and mutant strains of C. reinhardtii and Synechococcus sp. PCC 7002 were grown individually on Tris-Acetate-Phosphate (TAP) medium, a standard medium for $C$. reinhardtii, and $\mathrm{A}^{+}$ medium, a standard medium for Synechococcus sp. PCC 7002. Consistent with previous reports, the results of our preliminary experiments showed that the optimum temperature for the growth of C. reinhardtii is $\sim 30^{\circ} \mathrm{C}$ [20-22] and that for Synechococcus $7002 \sim 38^{\circ} \mathrm{C}[23]$. An increase in temperature from $30^{\circ} \mathrm{C}$ to $34^{\circ} \mathrm{C}$ and then to $38^{\circ} \mathrm{C}$
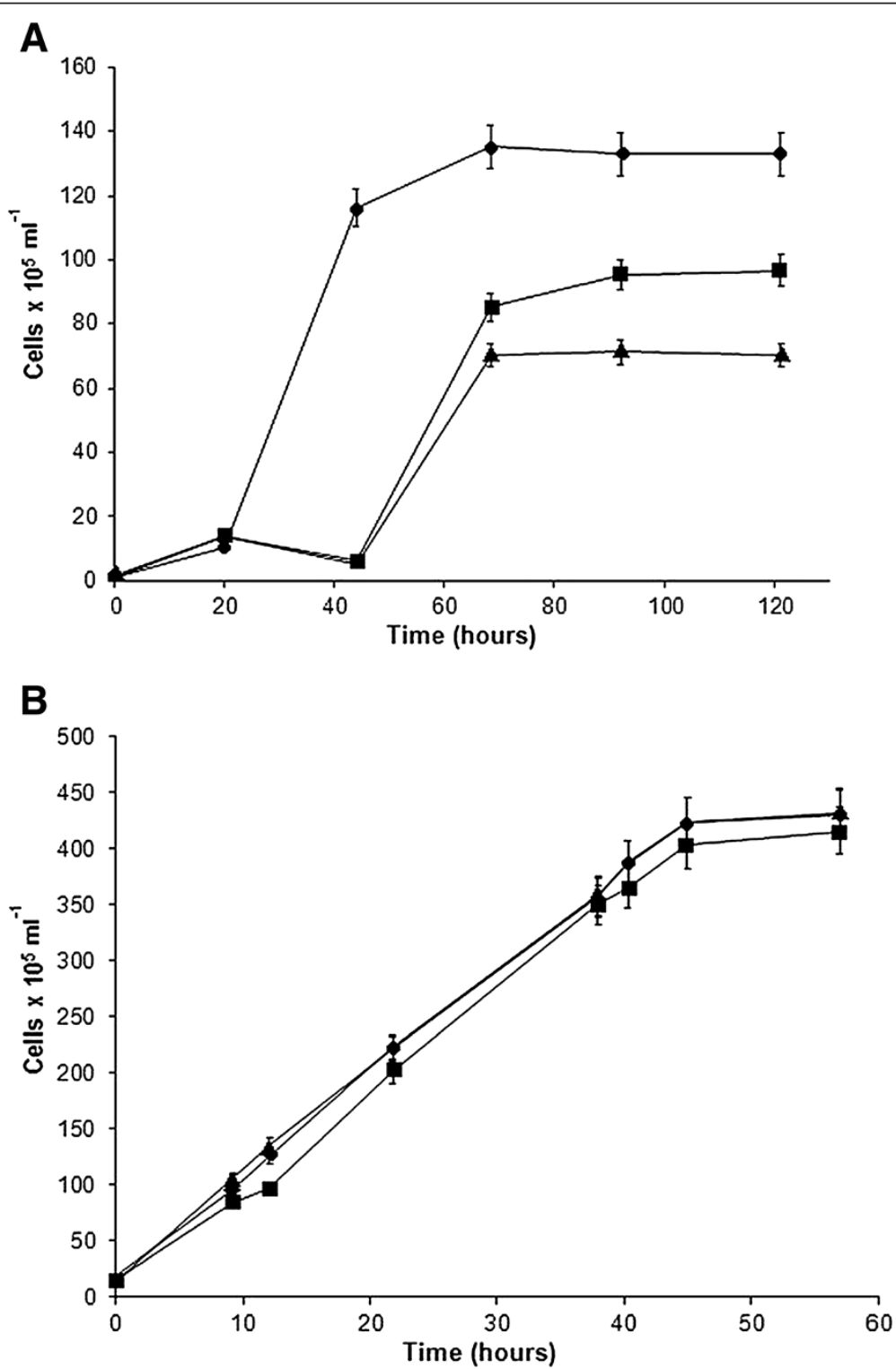

Figure 1 Effect of temperature on growth of $C$. reinhartdii and Synechococcus sp. PCC 7002. Cultures of $C$. reinhartdii (A) and Synechococcus sp. PCC 7002 (B) were grown at $30^{\circ} \mathrm{C}$ (circles), $34^{\circ} \mathrm{C}$ (squares), and $38^{\circ} \mathrm{C}$ (triangles). 
increased the lag phase in the $C$. reinhardtii cultures (Figure 1A). In contrast, decreasing the temperature from $38^{\circ} \mathrm{C}$ to $34^{\circ} \mathrm{C}$ and finally to $30^{\circ} \mathrm{C}$ did not significantly affect the growth of either wild-type (Figure 1B) or mutant strains of Synechococcus sp. PCC 7002 under the light intensities and $\mathrm{CO}_{2}$ concentrations used in this study (data not shown). Therefore subsequent co-culture optimizations were conducted at $30^{\circ} \mathrm{C}$.

\section{Effect of media composition on growth of $C$. reinhardtii and Synechococcus sp. PCC 7002}

The main difference between TAP medium (C. reinhardtii) and $\mathrm{A}^{+}$medium (Synechococcus sp. PCC 7002) is that medium $\mathrm{A}^{+}$is a marine medium that contains $300 \mathrm{mM}$ sodium chloride. Other differences include the use of ammonium chloride as the nitrogen source in TAP medium versus sodium nitrate in $\mathrm{A}^{+}$medium, the presence of acetate in TAP, and the presence of vitamin $B_{12}$ in $\mathrm{A}^{+}$medium. To accommodate the growth of both C. reinhardtii and Synechococcus sp. PCC 7002 in coculture, both the TAP and $\mathrm{A}^{+}$media were modified (henceforth referred to as modified TAP and modified $\mathrm{A}^{+}$, respectively). Modified TAP medium consists of TAP medium supplemented with sodium nitrate and vitamin $\mathrm{B}_{12}$; modified $\mathrm{A}^{+}$medium consists of standard $\mathrm{A}^{+}$medium supplemented with ammonium chloride and acetic acid, with the sodium chloride concentration reduced to $150 \mathrm{mM}$. (Additional file 1: Table S1). The results of our experiments showed that $C$. reinhardtii cultures are unable to grow on $\mathrm{A}^{+}$medium and/or modified $\mathrm{A}^{+}$medium at $30^{\circ} \mathrm{C}$ (Figure 2, and insert in Figure 2) and $38^{\circ} \mathrm{C}$ (data not shown). However, Synechococcus sp. PCC
7002 was able to grow on both TAP and modified TAP media at $30^{\circ} \mathrm{C}$ (Figure 2).

\section{Effect of acetate on growth of $C$. reinhardtii and Synechococcus sp. PCC 7002}

To investigate the effects of acetate on the growth of both wild-type and mutant cultures of $C$. reinhardtii and Synechococcus sp. PCC 7002, cultures were grown on TAP medium containing acetate and on a modified form of TAP medium that lacked acetate (termed co-culture medium). The results of these experiments showed that the growth rates of wild-type and mutant cultures of $C$. reinhartdii were higher in the presence of acetate when compared to cultures grown in the absence of acetate. Cultures of C. reinhardtii grown in acetate-free medium showed little growth under these conditions (Figure 3A). Although Synechococcus sp. PCC 7002 cultures grown without acetate had slightly lower final cell densities than cultures grown in the presence of acetate, the growth rates with and without acetate were similar for both wildtype and mutant strains (Figure 3B). During the growth of wild-type and sta 6 mutant strains of $C$. reinhardtii, acetate consumption correlated with an increase in cell number (Figure 4A). Acetate production by the $\operatorname{glg} A 1$ mutant of Synechococcus 7002 was higher than that of the wild type (Figure 4B).

\section{Optimizing co-cultures}

Based on the initial experiments, the sta 6 mutant of $C$. reinhardtii was grown on co-culture medium at $\mathrm{pH} 7.0$ and $30^{\circ} \mathrm{C}$ with the glgA1 mutant of Synechococcus sp. PCC 7002. To investigate the effect of initial cell number

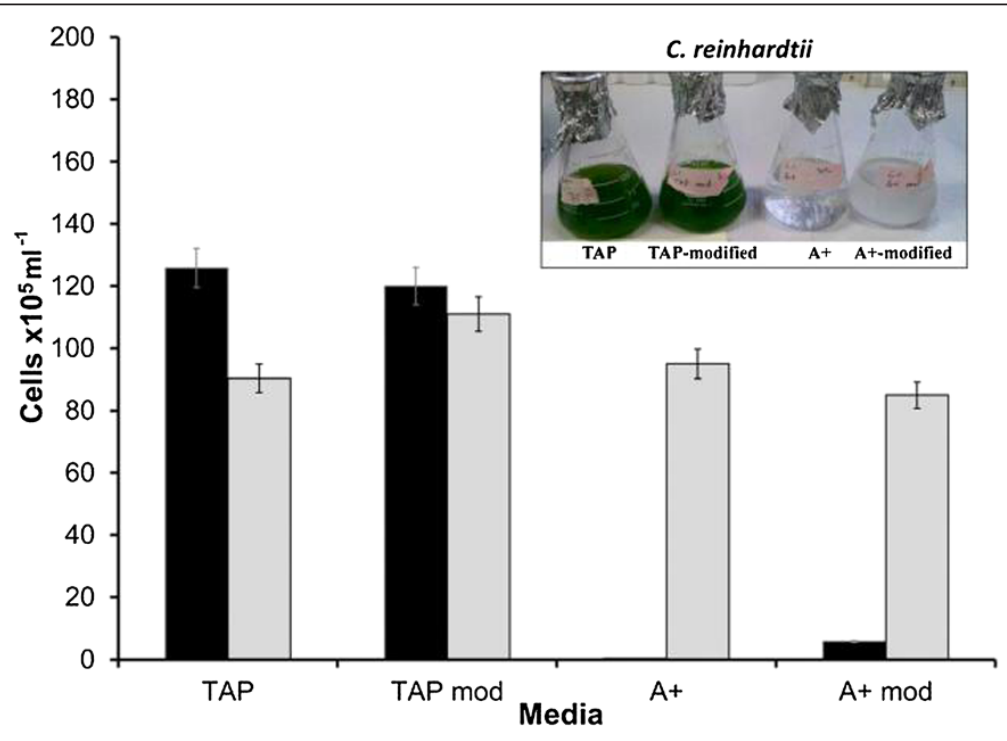

Figure 2 Growth of C. reinhartdii and Synechococcus sp. PCC 7002 on different types of media. Cultures of C. reinhartdii (black bars) and Synechococcus sp. PCC 7002 (gray bars) were grown on TAP, co-culture media (TAP mod), $\mathrm{A}^{+}$, modified $\mathrm{A}^{+}$media at $30^{\circ} \mathrm{C}$ after 124 hours. The difference in the media composition is described in the text and in the Methods section. 

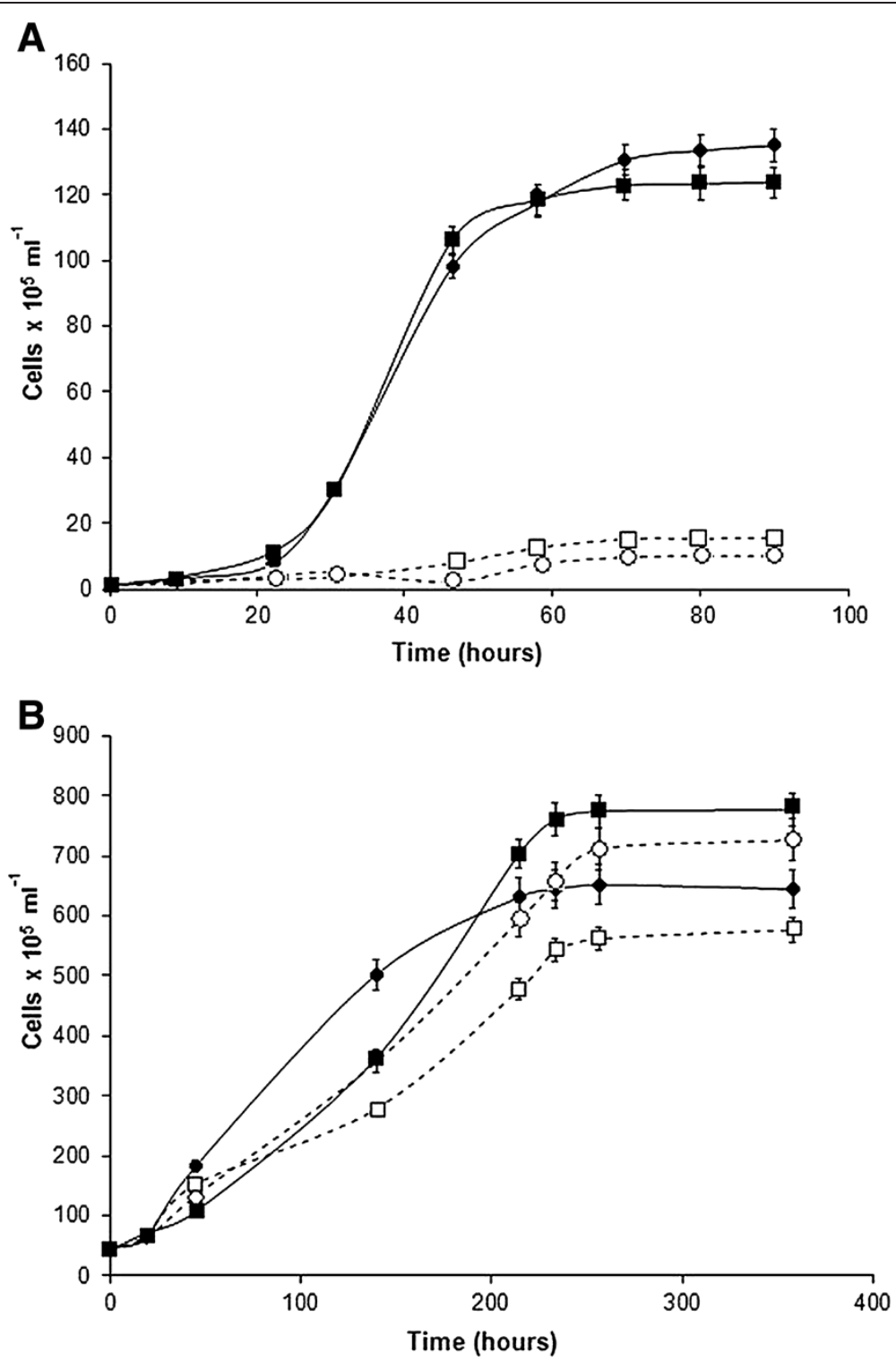

Figure 3 Effect of acetate on growth of C. reinhartdii and Synechococcus sp. PCC 7002. The cultures of C. reinhartdii (A) and Synechococcus sp. PCC 7002 (B) were grown in the presence (closed symbols) and absence (open symbols) of acetate. Both C. reinhartdii and Synechococcus sp. PCC 7002 wild-type cultures are shown in circles. The sta6 mutant of C. reinhartdii and the glgA mutant of Synechococcus sp. PCC 7002 are shown in squares.

in the inoculum during co-culturing of free cells, different initial ratios, 1:1 and 1:10, of C. reinhardtii to Synechococcus sp. PCC 7002 cells were tested. The ratio 1:10 was chosen because Synechococcus sp. PCC 7002 appeared to produce less acetate than required to produce optimal growth of C. reinhardtii, and it was rationalized that a larger number of Synechococcus sp. PCC 7002 cells might be advantageous in the co-cultures. However, the results of the co-culturing experiments with free cells revealed that Synechococcus sp. PCC 7002 cells grew faster than C. reinhardtii at both initial cell ratios and eventually took over the co-culture (data not shown). To avoid the problem of overgrowth by Synechococcus sp. PCC 7002, the cells were encapsulated in alginate beads to slow their growth (see Methods section for details). The growth of the $C$. reinhardtii sta 6 mutant in the presence of control (empty) beads in modified TAP media showed that the alginate encapsulating matrix had no effect on the growth of $C$. reinhardtii cells (data not shown). The results of the experiments using alginate-encapsulated Synechococcus sp. PCC 7002 cells showed that the growth of the lipid-accumulating $C$. reinhardtii sta6 strain could be supported by the presence of the acetate-producing Synechococcus sp. PCC 7002 glgA1 

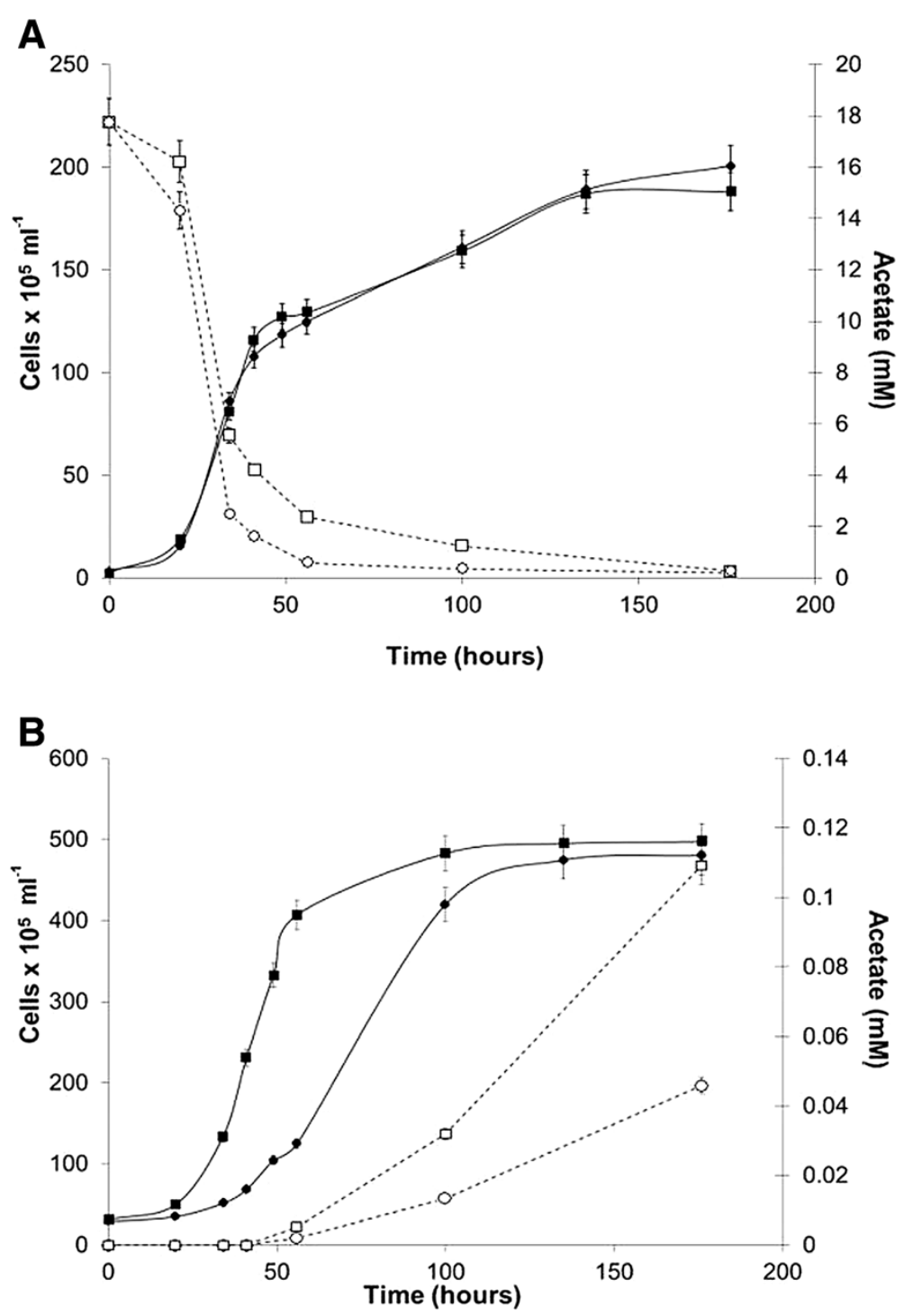

Figure 4 Growth and consumption of acetate by C. reinhartdii cultures, and growth and production of acetate by Synechococcus sp. PCC 7002 cultures. The cultures of wild-type (closed circles) and sta6 mutant (closed squares) of C. reinhartdii (A) and wild-type (closed circles) and glgA (closed squares) of Synechococcus sp. PCC 7002 (B) grown on co-culture media at pH 7.0 and $30^{\circ} \mathrm{C}$. Acetate consumption (A) by wild-type (open circles) and sta6 mutant (open squares) C. reinhartdii and production (B) by wild-type (open circles) and glgA mutant (open squares) Synechococcus sp. PCC 7002 were measured during the cell growth.

strain (Figure 5) and that immobilization controlled the growth of Synechococcus sp. PCC 7002 and kept the co-cultures from being overgrown.

\section{Conclusions}

We have developed media formulations and growth conditions that support co-cultures of wild-type and the acetate-producing glgA1 strain of the Synechococcus sp. PCC 7002 and wild-type and lipid-accumulating sta6 mutant of C. reinhardtii (Additional file 2: Figure S1). A temperature of $30^{\circ} \mathrm{C}$ supported the growth of both organisms; however, Synechococcus sp. PCC 7002 overtook the culture when both organisms were present as free cells. Alginate encapsulation was found to be an effective way to slow the growth of Synechococcus sp. PCC 7002 while at the same time allowing the production of sufficient acetate to stimulate growth and lipid storage of $C$. reinhardtii. The encapsulation of Synechococcus sp. PCC 7002 also provides a potential mechanism for separating and harvesting $C$. reinhardtii for lipids and recycling of the Synechococcus sp. PCC 7002 cells. The results reported here provide a strong proof of concept for supplanting the provision of costly medium components through co-culturing that can be optimized through metabolic engineering and implementation of enhanced acetate-producing cyanobacteria. 


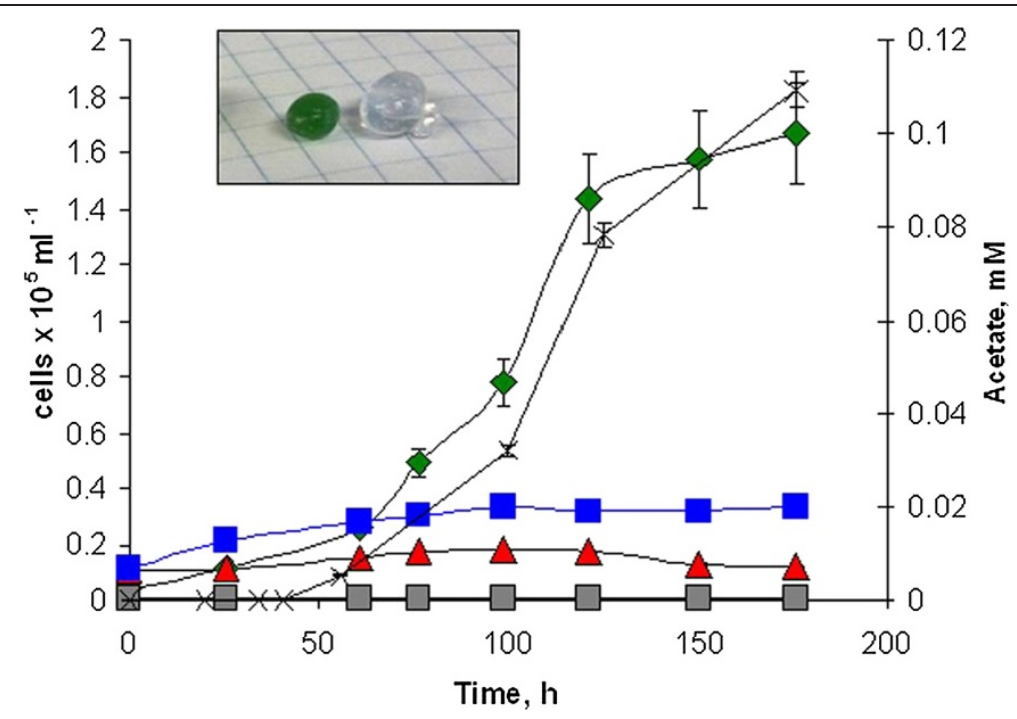

Figure 5 Co-culturing C. reinhartdii and Synechococcus sp. PCC 7002. The C. reinhartdii sta6 mutant was grown with alginate bead immobilized Synechococcus sp. PCC 7002 wild-type cells (blue squares), glgA1 cells (green diamonds), and with empty beads (red triangles) in co-culture on modified TAP media without acetate at pH 7.0. Growth of Synechococcus sp. PCC 7002 cells leaking out of the beads is shown in gray squares. Acetate production by alginate bead immobilized Synechococcus sp. PCC 7002 glgA1 mono-culture is shown in stars. The inset shows alginate beads of Synechococcus sp. (left) and an empty bead (right).

\section{Methods}

\section{Growth of microorganisms}

Inoculum cultures of both Synechococcus sp. PCC 7002 and C. reinhardtii $(25 \mathrm{ml})$ were prepared in standard growth media for each organism in 50-ml Erlenmeyer flasks oscillating at $100 \mathrm{rpm}$ at a constant illumination of $100 \mu \mathrm{mol}$ photons $\mathrm{m}^{-2} \mathrm{~s}^{-1}$ with warm white fluorescent light. Wild-type and $\operatorname{glgA1}$ knockout mutant strains of Synechococcus sp. PCC 7002 were grown in medium $\mathrm{A}^{+}(\mathrm{pH}=8.0)$ [24] (Additional file 1: Table S1) and were incubated at $38^{\circ} \mathrm{C}$ while sparging with $1 \% \mathrm{v} / \mathrm{v} \mathrm{CO}_{2}$ in air. Wild-type $C$. reinhardtii and sta 6 mutant strains were grown in TAP media $(\mathrm{pH}=7.0)$ incubated at $30^{\circ} \mathrm{C}$. The optical density was monitored at $750 \mathrm{~nm}$ (ThermoSpectronic Bio Mate 3 spectrophotometer) for Synechococcus sp. PCC 7002 and C. reinhardtii strains. Cultures were harvested by centrifugation for $10 \mathrm{~min}$ at $8,000 \times g$, washed in the medium to be used, centrifuged again, and finally resuspended in the appropriate medium and used to inoculate different culture conditions for coculturing. Optimal co-culturing conditions were determined by first growing wild-type Synechococcus sp. PCC 7002 and C. reinhardtii strains individually at $30^{\circ} \mathrm{C}, 34^{\circ} \mathrm{C}$, and $38^{\circ} \mathrm{C}$ on TAP medium (standard C. reinhardtii growth medium) or $\mathrm{A}^{+}$medium (standard Synechococcus sp. PCC 7002 growth medium). The formulation of the TAP media, $\mathrm{A}^{+}$medium, and modified derivatives of each can be found in the supplemental data (Additional file 1: Table S1). For the study, standard TAP medium was modified by eliminating acetic acid and supplementing with $1 \mathrm{~g} \mathrm{NaNO}_{3} \mathrm{~L}^{-1}$ and $4 \mu \mathrm{g}$ vitamin $\mathrm{B}_{12} \mathrm{~L}^{-1}$, and this formulation was termed co-culture medium. $\mathrm{A}^{+}$medium was supplemented with $7.5 \mathrm{~g} \mathrm{NH}_{4} \mathrm{Cl} \mathrm{L}^{-1}$ and $1 \mathrm{ml}$ glacial acetic acid $\mathrm{L}^{-1}$, and the concentration of $\mathrm{NaNO}_{3}$ and $\mathrm{NaCl}$ was reduced by $50 \%$. Co-cultures were inoculated with a mixture of seed cultures grown in the appropriate culture media, and the optical densities were monitored at both $600 \mathrm{~nm}$ and $750 \mathrm{~nm}$. The cultures were monitored for bacterial contamination by microscopic examination, and cell numbers were determined by direct cell counting with a hemocytometer.

\section{Cell immobilization}

Synechococcus sp. PCC 7002 cultures were harvested at an $\mathrm{OD}_{650} \mathrm{~nm}$ ranging from 0.8-1.0 (ThermoSpectronic Bio Mate 3 spectrophotometer) via centrifugation and resuspended in $1 / 5$ the original media volume, yielding a concentrated cell suspension. Alginate beads were made by dissolving $3 \mathrm{~g}$ of sodium alginate directly in $100 \mathrm{ml}$ of concentrated culture media and adding it dropwise with a syringe and needle into a $1 \%(\mathrm{w} / \mathrm{v})$ solution of $\mathrm{CaCl}_{2}$ in growth media from a height of at least $30 \mathrm{~cm}$ [25]. The bead size was controlled by needle gauge: $22 \mathrm{G}$ yields beads approximately $2 \mathrm{~mm}$ in diameter and $18 \mathrm{G}$ yields beads of $3 \mathrm{~mm}$, while 4 - $\mathrm{mm}$ beads are made directly from a 10-ml syringe without a needle. Beads were formed immediately and were allowed to harden further in the $\mathrm{CaCl}_{2}$ solution for $15 \mathrm{~min}$. After hardening, the beads were removed from the $\mathrm{CaCl}_{2}$ solution and added to fresh growth media. To prevent leakage of cells, a cell-free layer 
of alginate was used to coat the beads. To produce the coating, the beads were submerged in a $3 \%(\mathrm{w} / \mathrm{v})$ alginate solution in growth medium followed by transfer to a $1 \%$ $(\mathrm{w} / \mathrm{v})$ solution of $\mathrm{CaCl}_{2}$ in growth medium to allow hardening of the cell-free alginate layer.

\section{Acetate determination}

Acetate concentrations were determined by ${ }^{1} \mathrm{H}-\mathrm{NMR}$ [26]. Samples were centrifuged for $10 \mathrm{~min}$ at $14,000 \times g$ and $500 \mu \mathrm{l}$ of the supernatant was transferred to an NMR tube to which $50 \mu \mathrm{l}$ of $\mathrm{D}_{2} \mathrm{O}$ was added. Spectra were collected on a Bruker DRX500 NMR spectrometer operating at a frequency of $500.13 \mathrm{MHz}$ with a 1D NOESY pulse sequence and a 100-ms mixing time at $32 \mathrm{~K}$. Typically, 64 4.28-s scans were collected for each sample with a pre-saturation pulse to suppress the water signal.

\section{Additional files}

Additional file 1: Table S1. Media composition of TAP, $A^{+}$, modified TAP, modified $\mathrm{A}^{+}$per liter of $\mathrm{dH}_{2} \mathrm{O}$

Additional file 2: Figure S1. Growth and lipid accumulation of wild-type and sta6 mutant C. reinhardtii. Cultures of wild-type (closed squares, dotted line) and sta6 mutant (closed diamonds, dotted line) C. reinhardtii were grown on modified TAP media at $30^{\circ} \mathrm{C}$ in the presence of acetate. The lipid accumulation in wild-type (open squares, solid line) and sta6 mutant (open diamonds, solid line) C. reinhardtii cells was determined with Nile red stain after a 10-min incubation [1]. The amount of lipids accumulated after 42 hours growth of wild-type C. reinhardtii cells was chosen as $100 \%$.

\section{Competing interests}

The authors declare that they have no competing interests.

\section{Authors' contributions}

JBT and OAZ contributed equally in conducting the experiments. JWP, DAB, $M C P, O A Z$, and JBT designed the experiments, analyzed the data, and wrote the article. All authors read and approved the final manuscript.

\section{Acknowledgements}

The authors would like to thank Dr. Scott Busse, Interim Director of Montana State University NMR facility, for assistance in measuring the acetate concentrations. The project was supported by a grant from DOE Energy Efficiency and Renewable Energy (DE-EE0003136) to JWP and DAB, and AFOSR (FA9550-14-1-0147) to MCP and JWP.

\section{Author details}

${ }^{1}$ Department of Chemistry and Biochemistry, Montana State University, Bozeman, Montana 59717, USA. ²Department of Biochemistry and Molecular Biology, The Pennsylvania State University, University Park, Pennsylvania 16802, USA. ${ }^{3}$ Department of Chemistry and Geochemistry, Colorado School of Mines, Golden, Colorado 80401, USA.

Received: 5 June 2014 Accepted: 2 October 2014

Published online: 18 October 2014

\section{References}

1. Ren JZ, Manzardo A, Mazzi A, Fedele A, Scipioni A: Emergy analysis and sustainability efficiency analysis of different crop-based biodiesel in life cycle perspective. Scientific World J 2013, 2013:1-12.

2. Posten $C$, Schaub G: Microalgae and terrestrial biomass as source for fuels - a process view. J Biotechnol 2009, 142:64-69.

3. Schenk PM, Thomas-Hall SR, Stephens E, Marx UC, Mussgnug JH, Posten C, Kruse O, Hankamer B: Second generation biofuels: high-efficiency microalgae for biodiesel production. Bioenergy Res 2008, 1:20-43.

4. Dwidar M, Kim S, Jeon BS, Um Y, Mitchell RJ, Sang BI: Co-culturing a novel Bacillus strain with Clostridium tyrobutyricum ATCC 25755 to produce butyric acid from sucrose. Biotechnol Biofuels 2013, 6:35.

5. Hannon M, Gimpel J, Tran M, Rasala B, Mayfield S: Biofuels from algae: challenges and potential. Biofuels 2010, 1(5):763-784.

6. Campbell PK, Beer T, Batten D: Life cycle assessment of biodiesel production from microalgae in ponds. Bioresour Technol 2011, 102:50-56.

7. Beer LL, Boyd ES, Peters JW, Posewitz MC: Engineering algae for biohydrogen and biofuel production. Curr Opin Biotechnol 2009, 20:264-271

8. Radakovits R, Eduafo PM, Posewitz MC: Genetic engineering of fatty acid chain length in Phaeodactylum tricornutum. Metab Eng 2013, 13:89-95.

9. Lakaniemi AM, Hulatt CJ, Thomas DN, Tuovinen OH, Puhakka JA: Biogenic hydrogen and methane production from Chlorella vulgaris and Dunaliella tertiolecta biomass. Biotechnol Biofuels 2011, 4:34.

10. Wahlen BD, Willis RM, Seefeldt LC: Biodiesel production by simultaneous extraction and conversion of total lipids from microalgae, cyanobacteria, and wild mixed-cultures. Bioresour Technol 2011, 102:2724-2730.

11. Wang JF, Li RM, Lu D, Ma S, Yan YP, Li WJ: A quick isolation method for mutants with high lipid yield in oleaginous yeast. World J Microbiol Biotechnol 2009, 25:921-925.

12. Meuser JE, Ananyev G, Wittig LE, Kosourov S, Ghirardi ML, Seibert M, Dismukes GC, Posewitz MC: Phenotypic diversity of hydrogen production in chlorophycean algae reflects distinct anaerobic metabolisms. J Biotechnol 2009, 142:21-30

13. Stern DB, Witman GB: The Chlamydomonas Sourcebook: Organellar and Metabolic Processes. Kindle Edition ednth edition. Oxford UK: Academic Press; 1989:2.

14. Zabawinski C, Van den Koornhuyse N, D'Hulst C, Schlichting R, Giersch C, Delrue B, Lacroix JM, Preiss J, Ball S: Starchless mutants of Chlamydomonas reinhardtii lack the small subunit of a heterotetrameric ADP-glucose pyrophosphorylase. J Bacteriol 2001, 183:1069-1077.

15. Work VH, Radakovits R, Jinkerson RE, Meuser JE, Elliott LG, Vinyard DJ, Laurens LM, Dismukes GC, Posewitz MC: Increased lipid accumulation in the Chlamydomonas reinhardtii sta7-10 starchless isoamylase mutant and increased carbohydrate synthesis in complemented strains. Eukaryot Cell 2010, 9:1251-1261.

16. Sager $R$, Granick S: Nutritional studies with Chlamydomanas reinhardtii. Ann N Y Acad Sci 1953, 56:831-838.

17. McNeely K, Xu Y, Bennette N, Bryant DA, Dismukes GC: Redirecting reductant flux into hydrogen production via metabolic engineering of fermentative carbon metabolism in a cyanobacterium. Appl Environ Microbiol 2010, 76:5032-5038.

18. Xu Y, Guerra LT, Li ZK, Ludwig M, Dismukes GC, Bryant DA: Altered carbohydrate metabolism in glycogen synthase mutants of Synechococcus sp strain PCC 7002: Cell factories for soluble sugars. Metab Eng 2013, 16:56-67.

19. Guerra LT, Levitan O, Frada MJ, Sun JS, Falkowski PG, Dismukes GC: Regulatory branch points affecting protein and lipid biosynthesis in the diatom Phaeodactylum tricornutum. Biomass Bioenergy 2013, 59:306-315

20. Harris EH: The Chlamydomonas Sourcebook: Introduction to Chlamydomonas and Its Laboratory Use. Kindle Edition ednth edition. Oxford UK: Academic Press; 1989:1.

21. Tsygankov AA, Kosourov SN, Tolstygina IV, Ghirardi ML, Seibert M: Hydrogen production by sulfur-deprived Chlamydomonas reinhardtii under photoautotrophic conditions. Int J Hydrogen Energy 2006, 31:1574-1584

22. Laurinavichene TV, Fedorov AS, Ghirardi ML, Seibert M, Tsygankov AA: Demonstration of sustained hydrogen photoproduction by immobilized, sulfur-deprived Chlamydomonas reinhardtii cells. Int J Hydrogen Energy 2006, 31:659-667.

23. Ludwig M, Bryant DA: Synechococcus sp. strain PCC 7002 transcriptome: acclimation to temperature, salinity, oxidative stress, and mixotrophic growth conditions. Front Microbio/ 2012, 3:354

24. Stevens SE, Patterso.Co, Myers J: The production of hydrogen peroxide by blue-green algae - a survey. J Phycol 1973, 9:427-430 
25. Eldridge D: A novel approach to photosynthesis practicals. School Sci Rev 2004, 85:37-45.

26. Rajabzadeh M: Determination of unknown concentrations of sodium acetate using the method of standard addition and proton NMR: an experiment for the undergraduate analytical chemistry laboratory. J Chem Educ 2012, 89:1454-1457.

doi:10.1186/s13068-014-0154-2

Cite this article as: Therien et al:: Growth of Chlamydomonas reinhardtii in acetate-free medium when co-cultured with alginate-encapsulated, acetate-producing strains of Synechococcus sp. PCC 7002. Biotechnology for Biofuels 2014 7:154.

\section{Submit your next manuscript to BioMed Central and take full advantage of:}

- Convenient online submission

- Thorough peer review

- No space constraints or color figure charges

- Immediate publication on acceptance

- Inclusion in PubMed, CAS, Scopus and Google Scholar

- Research which is freely available for redistribution 